\title{
Piedad, impiedad y justicia en la polis (a propósito del Eutifrón de Platón)
}

\author{
José Pascual \\ Universidad Autónoma de Madrid \\ jose.pascual@uam.es \\ ORCID iD: https://orcid.org/0000-0002-9651-8028
}

\section{Piety, Impiety and Justice in the polis (about Plato's Euthyphro)}

\begin{abstract}
Este trabajo analiza la forma en que la piedad socrática y sus ideas religiosas, en un contexto histórico hostil al filósofo, se enfrentaban con la piedad popular y las creencias religiosas de la polis. De este modo, el escepticismo de Sócrates hacia los relatos mitológicos, la idea de que existía un único canon de virtud universal, aplicable tanto a las cosas divinas como humanas, y la separación de la piedad y la justicia de la voluntad de los dioses, le llevaron a socavar las bases de la religión griega que se fundamentaban en el temor y respeto a los dioses y en una práctica cultual tradicional que garantizaba la protección de los dioses necesaria para la supervivencia de la comunidad.
\end{abstract}

Palabras clave: Grecia antigua; Atenas; Sócrates; polis; religión; piedad; impiedad; justicia.
This paper analyzes the way in which Socratic piety and the religious ideas associated with it, in a context hostile to the philosopher, was in conflict with popular piety and the religious beliefs of the polis. Socrates' skepticism towards mythological tales, the idea that only a single canon of universal virtue existed that was applicable to both holy and human matters, as well as the separation of piety and justice from the divine will, led him to undermine the basis of Greek religion. This was founded on the fear and respect of the gods, as well as on a traditional cult practice that was supposed to guarantee the divine protection necessary for the survival of the community.

Key words: Ancient Greece; Athens; Socrates; Polis; Religion; Piety; Impiety; Justice.

Cómo citar este artículo / Citation: Pascual, José 2020: «Piedad, impiedad y justicia en la polis (a propósito del Eutifrón de Platón)», Emerita 88 (1), pp. 73-100.

En realidad, llevamos siglos haciéndonos las mismas preguntas: ¿Cómo fue posible que Sócrates fuera condenado a muerte? ¿Fue Sócrates un impío? ¿Ofendió a los dioses de su ciudad? ¿Sus ideas corrompían a la juventud ateniense? ¿Fue acusado injustamente? Y volvemos, una y otra vez, a la

Copyright: (C) 2020 CSIC. Este es un artículo de acceso abierto distribuido bajo los términos de la licencia de uso y distribución Creative Commons Reconocimiento 4.0 Internacional (CC BY 4.0). 
Atenas de aquella primavera de $399^{1}$, investigando, inquiriendo, indagando, y nos gustaría que aquel juicio nunca hubiera tenido lugar.

Ciertamente las enseñanzas socráticas y las circunstancias que rodearon su ejecución tienen un valor en sí, intrínseco, como descollante objeto de estudio, pero, también, la vida y el proceso de Sócrates poseen un valor paradigmático, trascendente, universal, que enfrenta a los hombres y mujeres contemporáneos con su propia conciencia. En primer lugar, tiene que ver con el valor del compromiso ético. Sócrates se transfigura así en el intelectual, el librepensador ${ }^{2}$, el simple ciudadano, atemporal, que dice lo que piensa, que no se calla, aunque sus ideas sean contrarias a lo común, que se opone a lo políticamente correcto. Aquel que une su discurso libre al coraje de defender hasta el final y con total determinación aquello en lo que cree. Y junto al papel del intelectual podemos preguntarnos: ¿cuál debe ser la relación entre el intelectual y la sociedad, entre el individuo y la colectividad? ${ }^{3} \mathrm{Y}$ otra pregunta inquietante: ¿cómo fue posible que la democracia más avanzada del mundo griego ${ }^{4}$, identificada en el imaginario occidental no poco con la nuestra, la escuela de Grecia ${ }^{5}$, la Hélade de la Hélade, ejecutara a uno de los más grandes filósofos y pensadores de la Antigüedad? En suma, el juicio de Sócrates viene a reflejar también nuestras propias preocupaciones contemporáneas y su condena pudiera llegar a condenarnos tanto a nosotros mismos cuanto que a nuestra propia sociedad. Todos quisiéramos ser Sócrates, pero nos asalta el temor de no serlo, y de que, en último término, figuremos en el lado de los que votaron contra él.

${ }^{1}$ Acerca de la importancia del juicio contra Sócrates sirvan como ejemplo Stone 1988, p. 3: «No other trial, except of Jesus, has left so vivid an impression on the imagination of Western man as that of Socrates», y Kraut 2000, p. 13: "The trial of Socrates is a landmark in our cultural history». Las obras consagradas a dicho proceso son demasiado numerosas para incluirlas aquí, si bien podemos mencionar a título de ejemplos: Kraut 1984; Stone 1988; Brickhouse y Smith 1989; Parker 2000, pp. 40-54; Nails 2006, pp. 5-20; Waterfield 2009.

2 Véase Janko 2006, pp. 48-62.

${ }^{3}$ Colaiaco 2001, p. 99: «The philosophic mission of Socrates brought him into conflict with the Athenians, raising the question of whether an individual should be free to challenge values fundamental to the community and whether he should be permitted to encourage others to do likewise».

${ }^{4}$ Nails 2006, p. 5: «Athens, birthplace of democracy, executed the philosopher Socrates in the year 399 BCE for the crime of impiety (asebeia), i.e., irreverence toward the gods of the polis».

${ }_{5}^{5}$ Th. II 41.1. 
Aunque no es necesario postular una única razón, la crítica moderna se ha dividido en torno a las causas de su procesamiento y condena. En primer lugar, se ha hecho especial énfasis en las motivaciones políticas, esto es, en los elementos antidemocráticos de su pensamiento y la relación con sus discípulos Alcibíades y Critias ${ }^{6}$. En otros casos, por el contrario, se ha destacado lo que podríamos llamar los aspectos culturales e históricos, es decir, la situación de la Atenas de la Postguerra y su actitud hacia los intelectuales ${ }^{7}$. Quizás en menor medida, a mi juicio, se han señalado los motivos propiamente religiosos ${ }^{8}$.

Platón, testigo directo (y parcial) de los acontecimientos, elaboró una largo y exculpatorio alegato. De hecho, narró la acusación y el juicio de Sócrates en cinco diálogos. Así, el Teeteto está dedicado a examinar la vida del filósofo; el Eutifrón se sitúa en el momento de la citación; la Apología se consagra al juicio y defensa de Sócrates; en el Critón, Sócrates rehúsa huir y en el Fedón se relata su ejecución 9 . El Eutifrón, el diálogo que aquí nos ocupa, se emplaza entre los primeros diálogos que escribió Platón ${ }^{10}$ y fue compuesto probablemente entre los años 393 y 389, en el período que llamamos de la Guerra de Corinto $^{11}$, cuando habían transcurrido ya entre seis y diez años de la condena y muerte de Sócrates. Es muy posible que las circunstancias de la Atenas del momento, enfrentada con Esparta y devuelta a su papel principal en Grecia, crearan las condiciones que posibilitaran sin temor su publicación. Pero, más allá de la fecha concreta de redacción, que es además objeto de debate, lo que nos interesa, como veremos más adelante, es el año en que se dispone la acción del Eutifrón, como en los otros cuatro diálogos, en 399, de manera que la situación por la que atravesaba Atenas en ese período pudo tener mucho que ver, efectivamente, desde el punto de vista de la arqueopsicología de masas, con la acusación y ejecución de Sócrates.

${ }^{6}$ Wood y Wood 1978; Stone 1988.

7 Connor 1991; Parker 1996.

${ }^{8}$ Bussanich 206, p. 220: «We have little reason to doubt that his religious beliefs were the main factor motivating the charges».

${ }^{9}$ Cf. Nails 2007, pp. 5-20.

${ }^{10}$ El orden probable de los cinco diálogos es como sigue: en primer lugar, fueron compuestos la Apología, el Eutifrón y el Critón, posteriormente el Fedón y, por último, el Teeteto (cf. Vlastos 1995, p. 135).

${ }^{11}$ Sobre este conflicto pueden consultarse Pascual 1997, pp. 63-80 y especialmente Fornis 2008 . 
En todo caso, nosotros no vamos a intentar aquí indagar pormenorizadamente en su pensamiento filosófico en general, ni en la piedad socrática ni en las creencias religiosas del filósofo, ni en el conjunto de la obra platónica o jenofontea. Tampoco nos introduciremos en la cuestión socrática, es decir, en la relación entre el Sócrates histórico y el de los Diálogos platónicos aunque, a nuestro juicio, el Sócrates que Platón nos presenta en el Eutifrón pudo estar mucho más próximo al personaje histórico que en el caso de las obras platónicas posteriores ${ }^{12}$. Nos centraremos en un único diálogo, el Eutifrón y, sobre todo, en la manera en que la piedad socrática y sus ideas religiosas se confrontaban con la piedad popular y las ideas religiosas comunitarias.

El Eutifrón relata el encuentro entre Sócrates y el adivino (mántis) Eutifrón, que es mencionado en otra obra platónica ${ }^{13}$. Es posible que dicho encuentro fuera ficticio, pero no lo son, ni mucho menos, el lugar en donde se desarrolla el diálogo, en el exterior de la Estoa o Pórtico real del Ágora de Atenas, ni el pretexto que sirve para dar principio a la narración, la vista previa de la acusación (anácrisis), y responden a un acontecimiento rigurosamente histórico: el momento en que Sócrates hubo de presentarse ante el arconte basileús ${ }^{14}$.

La acción del Eutifrón se localiza, pues, en el Ágora delante de la residencia del arconte basileús, la Estoa Real o Stoá Basíleios, si bien como dice Eutifrón, Sócrates solía frecuentar sobre todo el Liceo (2a). Esta localización, requerida ciertamente por la citación, no deja de tener sus implicaciones en el plano simbólico. Estamos en el Ágora, el centro de la vida cívica ateniense, que se disponía sobre una amplia explanada, de forma vagamente triangular, que se extendía a los pies de la colina del Colono Agoreo, entre el Areópago y el río Erídano. La propia Estoa Real fue descubierta en junio de 1970 e identificada gracias al relato de Pausanias y a tres basas inscritas halladas in situ y que recogen las dedicatorias de distintos arcontes basileis conmemorando su año en el cargo ${ }^{15}$. La Estoa se alzaba al pie de la ladera nororiental del Colono Agoreo, en la encrucijada de dos rutas que, desde el norte y noroeste, convergían en esta zona, y quedaba en un área que se en-

12 Cf. Vallejo Campos y Vigo 2017, pp. 140-141.

13 Pl., Cra. 396 d2-297 a1.

${ }^{14}$ En general sobre los aspectos legales: Ober 2011.

15 Paus. I 3.1, 14.6; Leslie Shear Jr. 1971, pp. 256-258, inv. núm. 7168, 7185, 7186. Cf. Wycherley 1973, pp. 21-25. Ahora pueden consultarse en $I G \mathrm{II}^{\prime} \mathrm{III}^{3}(4) .41,95,113$. 
contraba más baja del nivel general del Ágora, de manera que su planta se ubicaba a 3,02 m. por debajo de la contigua Estoa de Zeus Eleuterio. Se trataba de uno de los lugares más importantes de la vida pública ateniense, si bien en realidad no era más que un modesto edificio, construido a finales del siglo VI, en torno quizá al período de las reformas de Clístenes, y cuyas dimensiones exteriores comprendían c. 7,57 por 17,72 m. En conjunto, el edificio, dotado de un pórtico octástilo, sumaba unos 100 metros cuadrados ${ }^{16} \mathrm{y}$ enfrente del mismo se alzaba también un altar ${ }^{17}$.

La Estoa servía de residencia oficial al arconte basileús y a sus dos ayudantes (páredroi). Todos los arcontes atenienses realizaban el juramento de guardar las leyes y no aceptar sobornos en la Estoa Real sobre una piedra ${ }^{18}$. Quizá este célebre líthos pudo ser un gran bloque de caliza, de color tostado, que mide c. $1 \mathrm{~m}$ de ancho, $3 \mathrm{~m}$ de longitud y $0,40 \mathrm{~m}$ de alto, que se encontró junto al estilóbato, algo más al norte del punto medio de la Estoa, y cuya función no es arquitectónica ${ }^{19}$. En lo que aquí nos concierne específicamente, el arconte basileús extendía su responsabilidad sobre materias sagradas, por ejemplo, supervisaba los misterios eleusinos o los sacrificios ancestrales. Como consecuencia de estas competencias religiosas, instruía también las causas por impiedad y todas las formas de homicidio ${ }^{20}$.

Básicamente el sistema jurídico ateniense distinguía dos grandes tipos de acusaciones, la díke idía, la acusación privada, que dirimía causas entre ciudadanos, y la dike demosía, que atendía no a los litigios interpuestos entre ciudadanos, sino a la acción que emprendía un ciudadano cuando pensaba que otro atacaba las leyes de la polis y que, por eso mismo, designamos como acusación pública. Un tipo especial de díke demosía era la graphé, que quizá todavía en época de Sócrates era la única acusación que se ponía por escrito, de ahí su nombre, si bien a largo del siglo IV este procedimiento se generaliza para otras acciones ${ }^{21}$. Sócrates dice expresamente que Meleto había presentado una graphé y no una díke ${ }^{22}$, idía se entiende, que le acusaba ante la

\footnotetext{
${ }^{16}$ Leslie Shear Jr. 1971, pp. 243-255; 1975, pp. 365-370; Camp 2001, pp. 44-46.

${ }^{17}$ Dem. LIV 26.

${ }_{18}$ Arist., Ath. 7.1; Poll., VIII 8.86.

${ }^{19}$ Leslie Shear Jr. 1971, pp. 251-252; Prior 2019, p. 50.

${ }^{20}$ Cf. Harrison 1971, pp. 8-9.

${ }^{21}$ Harrison 1971, pp. 75-78; MacDowell 1978, p. 57.

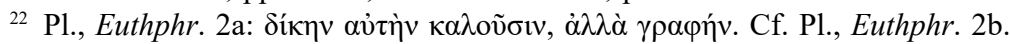




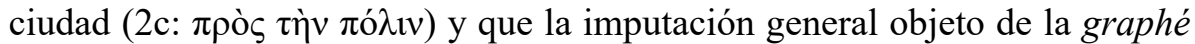
era la impiedad o asébeia $(5 \mathrm{c})^{23}$. Ya que la piedad era entendida como participación en la vida religiosa ateniense y constituía una obligación cívica, la persecución de la impiedad era un acto de interés comunitario ${ }^{24}$. Es probable que existiera una ley escrita sobre la impiedad en Atenas, más bien quizá un corpus jurídico relativo a la impiedad; sin embargo, debido a que dicho delito fue dejado deliberadamente ambiguo, se requería especificación. Por consiguiente, los cargos concretos contra Sócrates fueron, en el orden en que aparecen en el Eutifrón, los siguientes: Sócrates corrompía a la juventud (3a:

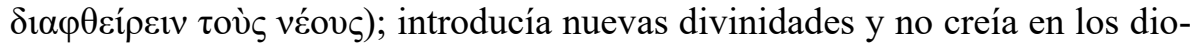

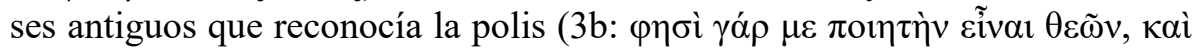

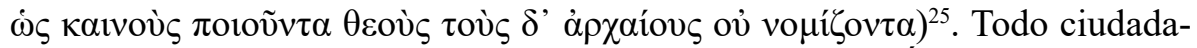
no podía unirse a la acusación y sabemos que lo hicieron Ánito de Eunimo y Licón de Tórico. La acusación había sido aceptada y, por tanto, se había publicado en tablillas blancas en el Ágora, en las estatuas de los Héroes epónimos, fijando un día para la citación o vista preliminar previa al juicio. Al menos cuatro días debían pasar entre la notificación y la audiencia preliminar y Sócrates estaba obligado a comparecer personalmente ${ }^{26}$. Conviene, en definitiva, tener presente el simbolismo cívico, religioso y legal de la Estoa Real, en cuya fachada Platón enmarca la acción, y que pudo tener que ver precisamente con la elección del escenario del diálogo.

De este modo, justo en el día en que tenía lugar la comparecencia, ante la Estoa Real y antes de entrar a la vista previa, Sócrates se encuentra con Eutifrón. Éste había interpuesto una acusación por homicidio (dike phónou) contra su propio padre, pues su progenitor, cuando estaba de cleruco en $\mathrm{Na}$ $\operatorname{xos}^{27}$, había dejado morir de frío e inanición, mientras enviaba a Atenas un

${ }^{23}$ MacDowell 1978, pp. 197-199; Smith y Wooddruff 2000, pp. 3-4; Nails 2006, pp. 6-11. Cf. Pl., Ap. 3b-d; 5a-c; 12e; 15e-16a. Sobre los tres acusadores véase, en general, Stone 1988, pp. 174-180. Meleto: Pl., Euthphr. 2b; Pl., Ap. 19b-c. Licón: Pl., Ap. 23e. Ánito: Pl., Men. 90a, 91c, 92e; Pl., Lach. 197d; X., Ap. XXI 1-2; Arist., Ath. 27.3-5; 34.3; Plácido 1984-85, pp. 7-13.

${ }^{24}$ Nails 2006, p. 6.

${ }^{25}$ McPherran 2005, p. 9; Nails 2006, p. 11. Cf. Pl., Ap. 24b-c; X., Mem. I 1.1; D.L. II 40. Sobre la corrupción a la juventud véase Euben 1997.

${ }^{26}$ Harrison 1971, pp. 94-105; MacDowell 1978, pp. 240-242.

${ }^{27}$ La cleruquía de Naxos fue establecida por Pericles en 447 y contaba con quinientos clerucos atenienses (cf. Th. I 98.4; D.S. XI 88.3; XII 6.2; Plu., Per. 11.5). 
mensajero para consultar a un exégeta, un intérprete de leyes sagradas (4c-d), a uno de sus jornaleros que, ebrio, había degollado a un esclavo en un altercado. Según Eutifrón, no importaba que el muerto o el asesino fueran un pariente o un extraño sino que, como se trataba de un asesinato injusto, se debía denunciar siempre, pues, de no hacerlo, la impiedad, que conllevaba la polución religiosa o míasma, recaería no sólo sobre su padre, sino también sobre él mismo y sobre toda su familia $(4 b-c)^{28}$.

Cabría preguntarse la razón por la cual Platón escogió a Eutifrón como interlocutor de Sócrates. Platón destaca en varias ocasiones a lo largo del diálogo la condición de experto en materias religiosas de Eutifrón y, de hecho, el mismo Eutifrón dice que su conocimiento en estos asuntos le diferencia y le sitúa por encima de la mayoría de los hombres. Así, frente a su padre, su familia y la mayoría de los atenienses, que desconocen la posición de lo divino con respecto a lo pío o la impiedad, él dice conocer con precisión en qué consisten ambos (4a-b; 4e-5a). Ciertamente toda persona desea en su fuero interno, ya sea en la Antigüedad o en nuestro mundo contemporáneo, conocer lo que le depara el porvenir con la finalidad de evitar los males o esperar, anhelantes, los bienes. De acuerdo con la creencia griega, los dioses dispensaban libremente a los mortales signos que ilustraban sobre su futuro. Para interpretar de manera convincente dichos signos, se requería un don carismático, la inspiración, que era otorgada por los dioses a determinadas personas en concreto, a los adivinos. De este modo, el adivino, por su capacidad para conocer los designios de los dioses, se convertía, por extensión, en el prototipo de hombre sabio ${ }^{29}$. Evidentemente la inspiración, una gracia divina, sólo podía recaer sobre un hombre piadoso, aquel cuyo conocimiento de la piedad y su actuación piadosa le hacían precisamente merecedor del favor de los dioses. Así, Eutifrón es mostrado como una persona versada en asuntos religiosos, sabia y piadosa, que conoce lo que es y significa la piedad y que actúa siempre piadosamente. Es, por lo tanto, el conocimiento técnico en relación con los dioses y, por consiguiente, de lo que era piadoso o impío, lo que hacían de Eutifrón un interlocutor adecuado, por encima del común de los ciudadanos atenienses, para que Sócrates diera principio a su indagación sobre la piedad. Quizás pueda pensarse también que Platón estableció una

${ }^{28}$ Cf. Burkert 2007, pp. 105-110; Bendlin 2007, pp. 178-179.

${ }_{29}$ Pl., Euthphr. 3d; Burkert 2007, pp. 152-155; Bonnechere 2007, pp. 145-159. 
suerte de asociación entre Sócrates, que escuchaba una voz demónica, y Eutifrón, que pensaba que estaba inspirado por la divinidad. Es muy probable, asimismo, que la denuncia de Eutifrón respondiera a un caso real que Platón pudo utilizar para confrontarlo con la acusación contra Sócrates.

Sócrates solicita a Eutifrón, en consecuencia, que le precise, como mántis, esto es, como experto en tales asuntos, lo que es piadoso o impío (5d: $\Lambda \varepsilon ́ \gamma \varepsilon$

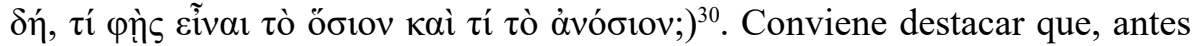
que eusebés, pío, o asebés, impío, en el Eutifrón Platón emplea respectivamente con preferencia y como sinónimos hósios y anósios ${ }^{31}$. El significado básico de hósios puede delimitarse como 'permitido por o agradable a los dioses' y hacía referencia fundamentalmente a las relaciones que debían establecerse entre los dioses y los hombres. Dichas relaciones debían atenerse a ciertas normas para que pudieran considerarse piadosas, esto es, aquello que estaba prescrito o permitido por la ley divina. Como ello producía, en la relación entre los dioses y los hombres, una situación justa, hósios se asociaba con frecuencia a díkaios, o justo, y se oponía a anósios o impío. En consecuencia, hósios incluía también la noción de 'justicia', como ilustra un epigrama funerario, dedicado a un tal Sosícrates, del que se nos dice que murió no de un modo hósios, «sino por muerte injusta», ö $\theta^{\prime} v^{\prime}$ ' o<نे $>\chi \dot{o} \sigma i ́ \omega \varsigma$, $\dot{\alpha} \lambda \lambda$,

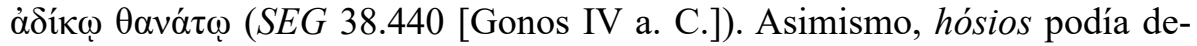
notar pureza ya que la impureza o contaminación, míasma, desagradaba y ofendía a los dioses ${ }^{32}$. En la práctica, hósios se plasmaba esencialmente en un comportamiento ritual correcto, en una ortopraxis diríamos. Es en esta múltiple e interrelacionada connotación, que aúna piedad, justicia, pureza y ritual, en el que hósios va a ser empleado por Platón. Por último, en las relaciones que se entablaban entre los mismos hombres, hósios indicaba también un tratamiento apropiado del prójimo.

Eutifrón afirma, en la que es su primera definición sobre la piedad (hósios), que ésta reside en acusar al que ha cometido un delito, ya sea un homicidio o el robo de cosas sagradas, mientras que la impiedad (anósios) consiste en no hacerlo, aunque el culpable sea un pariente y no cualquier otro

${ }^{30}$ Cf. Pl., Euthphr. 4d; West 1998, p. 12; McPherran 1999, pp. 31-36; Prior 2019, p. 58.

31 Platón emplea a lo largo del Eutifrón hósios sesenta y cinco veces y anósios veintiuna, frente a únicamente tres veces eusebés (5a, 12e bis) o dos asebés (5c, 14b).

${ }^{32}$ Zaidman y Schmitt-Pantel 2002, pp. 8-13; Bremmer 2006, p. 22; Burkert 2007, pp. 357-360. 
$(5 \mathrm{~d})^{33}$. Es decir, la piedad consiste en proceder contra los que cometen alguna injusticia. Eutifrón añade a esta respuesta un méga tekmérion, una prueba, que apoya su afirmación: todo el mundo está de acuerdo en que Zeus, el mejor y más justo de todos los dioses, encadenó a su propio padre, Crono, porque devoró a sus hijos injustamente. Crono, a su vez, mutiló a su padre, Urano, por injusticias semejantes (5e-6a) ${ }^{34}$. Estas acciones recogidas en los relatos míticos, permiten, según Eutifrón, conocer la voluntad de los dioses y fundar un nómos no escrito sobre la piedad. La denuncia contra su propio padre se enmarcaría precisamente en este nómos, de modo que lo que Eutifrón está haciendo al entablar dicha causa no es otra cosa que obedecer la voluntad de los dioses y las normas divinas. Así, el comportamiento piadoso deviene, en el ámbito humano, según el adivino, en una emulación de los dioses.

Pero Sócrates se muestra escéptico ante los relatos de los dioses ${ }^{35}$ e introduce una pregunta demoledora: «¿Crees tú verdaderamente que estas cosas

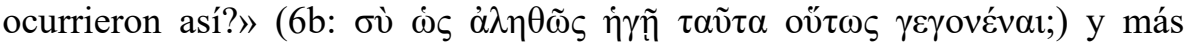
adelante inquiere: «¿Diremos que estas cosas son verdaderas?» (6c: $\tau \alpha \tilde{v} \tau \alpha$

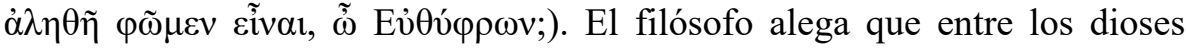
existen muchos desacuerdos similares a los de Zeus y Crono y que éstos disputan constantemente entre sí $(6 \mathrm{~b} ; 6 \mathrm{c})$. Además le hace notar a Eutifrón que él le ha preguntado no por uno o dos casos de piedad (6d), sino que busca la característica universal de la piedad, una idea (eídos), un patrón, una medida completamente segura para determinar lo que es piadoso o no en cualquier acción (6d-e $)^{36}$. En realidad, en opinión de Sócrates, lo que Eutifrón plantea no es una definición de la piedad, sino sólo un ejemplo de lo que es piadoso. Introduce una definición subjetiva de la piedad que se opone a la concepción socrática del carácter universal de la piedad ${ }^{37}$.

De esta manera, Sócrates está buscando la definición de la piedad, no una definición de un acto piadoso, e implícitamente está apuntando que dicha definición puede alcanzarse mediante el intelecto, a través de la razón. Afirma, en suma, la posibilidad de alcanzar un conocimiento objetivo de la pie-

\footnotetext{
33 McPherran 2005, pp. 2-3; 2011, p. 116.

34 Sobre este episodio puede verse Hes., Th. 132-182, 453-506, 617-819.

35 Cf. Pl., Euthphr: 6a-c.

36 West 1998, p. 13; McPherran 1999, pp. 36-38.

37 Prior 2019, pp. 55-60.
} 
dad, de establecer un principio racional que fundamente toda acción piadosa y que sea universalmente válido para todo tiempo, lugar y circunstancia ${ }^{38}$. Este intelectualismo socrático, que proclama la primacía de lo racional, aunque tenga en cuenta aspectos emocionales y volitivos ${ }^{39}$, convierte al conocimiento objetivo y racional de la piedad en una condición necesaria $\mathrm{y}$, al mismo tiempo, suficiente de la misma ${ }^{40}$. La enunciación de un principio racional de lo que es piadoso, le lleva, en el marco de la teoría platónica de las ideas, al esencialismo, esto es, a establecer objetivamente la esencia, la forma o naturaleza de la piedad (eídos, 5d4, 6d, 6e 3), un canon universal que hace que actos semejantes sean piadosos ${ }^{41}$. En consecuencia, la multiplicidad de los actos piadosos sólo se explica por la forma única e idéntica de la piedad, y un acto en sí mismo no es piadoso si no tiene en cuenta el modelo o criterio objetivo de valoración, el parádeigma ${ }^{42}$, de aquello que es piadoso ${ }^{43}$. Pero, además y en lo aquí nos concierne específicamente, ya en la refutación de la primera definición de Eutifrón, Sócrates ha comenzado a cuestionar los mitos griegos sobre los que se basaba no sólo la argumentación de Eutifrón, sino buena parte de la religiosidad griega.

Eutifrón intenta ahora remontarse desde su caso particular al principio general que Sócrates le ha pedido y asegura, en su segunda definición, que

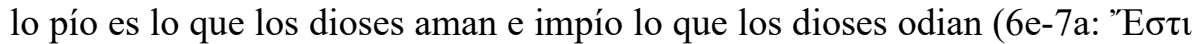

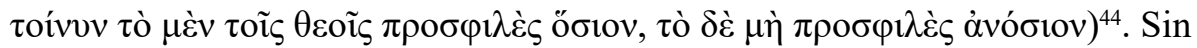
embargo, Sócrates le vuelve a indicar que los dioses conspiran, disputan y se enemistan entre ellos constantemente, del mismo modo que los hombres, y que estas discrepancias se producen a causa de que los dioses no están de acuerdo acerca de lo que es bello, justo o bueno. Por lo tanto, como las mismas cosas pueden ser consideradas justas, bellas o buenas por unos dioses e injustas, feas o malas por otros, se sigue que las mismas cosas serían, a un tiempo, pías e impías (7b-8d). Pero, como necesariamente todos estos con-

${ }^{38}$ Vallejo Campos y Vigo 2017, pp. 147, 185.

39 Vallejo Campos y Vigo 2017, pp. 132-135. Sobre los aspectos emocionales y volitivos del intelectualismo socrático: Segvic 2006.

${ }^{40}$ Vallejo Campos y Vigo 2017, pp. 138-140.

${ }^{41}$ Vallejo Campos y Vigo 2017, pp. 147-149, 182.

${ }^{42} \mathrm{Pl}$., Euthphr.6e.

${ }_{43}$ McPherran 2011, p. 115; Vallejo Campos y Vigo 2017, pp. 183-185.

${ }^{44}$ McPherran 2011, p. 117; Vallejo Campos y Vigo 2017, p. 151. Cf. P1., Euthphr. 10c. 
ceptos deben ser opuestos, así lo pío ha de ser lo opuesto a lo impío, Sócrates extrae la principal conclusión de esta primera parte: lo que los dioses aman determina sólo lo que es amado por ellos y no lo que es pío ${ }^{45}$.

Sin embargo, más allá de la confrontación entre Eutifrón y Sócrates, lo que a nosotros nos interesa exponer aquí principalmente se refiere a la relación que puede establecerse entre las opiniones de ambos, del adivino y del filósofo, con la creencia tradicional ateniense y, por extensión, griega. Y es que ya en esta primera parte del diálogo tanto Eutifrón como Sócrates se han apartado de la tradición. Ahora bien, si afirmamos esto, que ambos se han alejado de la piedad tradicional, debemos preguntarnos: ¿en qué consistía la piedad tradicional? ¿Qué entendía un ateniense o un griego por un comportamiento piadoso?

Como hemos visto, Eutifrón había procedido contra su padre y lo había hecho en contra de la costumbre tradicional, ya que dicha acusación violaba los cánones de piedad filial y así pensaban, como el mismo Eutifrón nos dice, su padre y el resto de su familia (4d-e). De hecho, el padre denunciado y el resto de la familia consideran que la impiedad se había producido precisamente al denunciar Eutifrón a su progenitor, de manera que el acto impío había sido cometido por el adivino y no por su padre (4d). Por su parte, los atenienses se habían burlado con frecuencia en el pasado del propio Eutifrón y creían que esta denuncia era también grotesca (3b, d, e). Esto es, la mayoría de los ciudadanos atenienses eran de la opinión del padre y de la familia de Eutifrón y contrarios al adivino ya que, en la mentalidad griega, el comportamiento adecuado con respecto a los progenitores era también hósios. En consecuencia, la eusébeia definía en la costumbre griega no sólo la relación con los dioses, sino que entrañaba también una determinada conducta hacia los parientes, la patria y los antepasados. Eutifrón se separaba también de la tradición al considerar que existía un mismo canon de virtud para las cosas humanas y divinas, mientras que, como veremos, comúnmente se defendía la existencia de dos diferentes categorías de conducta, una humana y otra divina. Así, frente a la opinión habitual griega, Eutifrón cree, sin embargo, que la piedad es unitaria y unívoca.

Por su parte, Sócrates nos presenta ya desde el principio del Eutifrón dos de sus principales postulados religiosos: la definición de piedad se debe apli-

\footnotetext{
${ }^{45}$ West 1998, p. 13; McPherran 1999, pp. 39-42.
} 
car a toda acción pía (5d) y, dado su rechazo a la violencia y enemistad divina, está obligado a defender que existe un canon universal de justicia y piedad para todas las cosas, divinas y humanas (2a), que, por lo tanto, los dioses son perfectamente justos y buenos ( $2 \mathrm{~b}$ ) y que, en consecuencia, no pueden experimentar divergencias morales entre ellos. En ambos puntos está de acuerdo con Eutifrón. Empero Sócrates no parece suscribir la veracidad de los relatos mitológicos y, al refutar la argumentación de Eutifrón, el filósofo rechaza también que se le presenten como prueba los actos de los dioses que se recogen en dichas tradiciones míticas. La razón es evidente puesto que la aceptación del material mítico implicaría una contradicción lógica con sus postulados principales: toda acción pía es necesariamente piadosa y justa, existe una definición de piedad universalmente válida y los dioses son siempre y necesariamente piadosos. Si lo pío es lo que aman los dioses porque es justo, lo piadoso no puede ser aquello que aman los dioses de la mitología puesto que en ella se recogen un sinfín de acciones divinas injustas. En este sentido, Sócrates está introduciendo una doble negación: los actos recogidos en la mitología no tienen valor alguno para conocer los deseos divinos y, de manera aún más dramática, la conducta de los dioses tal y como se nos muestra en estos relatos no tiene valor normativo alguno, esto es, no puede ser convertida en ley ${ }^{46}$. En suma, si la piedad reside en acatar la voluntad de los dioses, normada por la tradición, ni la voluntad de los dioses ni el fundamento de las leyes divinas pueden encontrarse en las narraciones mitológicas.

Tales ideas socráticas sobre la piedad y la mitología se oponen frontalmente a las concepciones asentadas en el politeuma ateniense, el cuerpo cívico que constituía la polis. En primer lugar, la definición de la piedad como aquello que los dioses aman se enfrentaba a la creencia popular de que los dioses son caprichosos y no tienen una conducta uniforme ${ }^{47}$. La tradición solventaba así la contradicción de los relatos míticos que mostraban a los dioses cometiendo actos que eran claramente injustos. En segundo lugar y de una manera aterradora para un ateniense y para todo griego, Sócrates está afirmando que la mitología podría no enseñarnos nada sobre la piedad y ello podía, como vamos a ver, llevarle a cuestionar, o incluso a negar, la base de la religión griega que se asentaba precisamente sobre estas tradiciones míticas.

${ }^{46}$ Herrmann 2007, p. 389.

${ }^{47}$ Smith y Woodruff 2000, p. 6; McPherran 2005, p. 6; 2011, p. 113. Sobre la religiosidad ateniense puede consultarse Parker 2005, esp. pp. 37-78, 89-115, 387-443. 
En este sentido, podríamos preguntarnos si los griegos creían en sus relatos mitológicos y probablemente en vano buscaríamos una respuesta. Ciertamente los mitos variaban de lugar en lugar y cada polis disponía de su propio material mítico, de su propio sistema religioso, aunque se solapara obviamente con la religión griega común; pero, más allá de las oscilaciones en un mismo mito o de la aceptación mayor o menor de un relato concreto, la clave, a mi juicio, se hallaba en la función que los mitos cumplían en la polis, en el seno de la comunidad ciudadana.

En efecto, lo que enseñaban los relatos míticos era ante todo y en primer lugar el temor y el respeto a los dioses ${ }^{48}$. Aristóteles lo expresa con toda lucidez. Para el de Estagira es una certeza filosófica la existencia de los dioses: «El resto [mito y rito] ha sido añadido míticamente con vistas a persuadir a la gente y en beneficio de las leyes y de lo conveniente» (Metaph. 1074b 1-8). Se trataba de lo opuesto al esteticismo amoral, como dice Isócrates (XI 25): «Aquellos que nos han inculcado este temor a los dioses han conseguido con ello que no nos comportemos los unos con los otros como animales». Es, pues, el temor a los dioses y por tanto la actitud hacia ellos, es decir, la piedad, el fundamento del código ético que hacía posible las relaciones humanas y en último término, la misma existencia de la polis. Y es que los dioses griegos no podían concedernos la vida, pero sí podían destruirnos. Como la religión griega no conocía el concepto de diablo, para inspirar temor, todos los dioses tenían su lado oscuro y peligroso, protegían un ámbito que consideraban exclusivo e intervenían cuando estimaban que éste no era respetado, imponiendo su voluntad de una manera a menudo trágica para el hombre. Los dioses exigían obligaciones a los hombres ${ }^{49}$. Como ellos daban lo bueno y lo malo, era lógico el deseo humano de ofrecer dones convenientes, agradables a los dioses, con la esperanza de obtener su ayuda o favor y de evitar todo aquello que pudiera ofenderles y provocar su venganza. Y la forma de hacer algo sagrado, piadoso, hósios, que fuera del agrado de los dioses, no era otra que rendirles culto. Así, la eusébeia, la piedad, ante todo el temor reverencial y el respeto a los dioses, se expresaba en el culto ${ }^{50}$ y ello conllevaba que, en definitiva, en la religión griega las prácticas (ortopraxis) fueran tan importantes o más que las creencias (ortodoxia).

48 Bremmer 2006, pp. 23-24; Burkert 2007, pp. 293-295.

${ }_{49} \mathrm{Pl}$., Euthphr. 12a-b; Burkert 2007, pp. 254-255.

${ }_{50}$ Zaidman y Schmitt-Pantel 2002, pp. 23-24; Bremmer 2006, p. 93; Burkert 2007, pp. 364-365. 
El cuestionamiento de los relatos míticos socavaba no sólo la concepción griega de divinidad, sino que afectaba de una manera pavorosa a la eficacia de los sacrificios que estaban en la misma esencia de la religión ${ }^{51}$ y que serán más adelante cuestionados en el mismo diálogo (14c-e).

En efecto, la creencia tradicional griega unía mito, rito, culto sacrificial y plegaria y, aunque es cierto que el rito va acompañado de la esperanza de que produzca ciertos efectos, nunca se puede contar con ello de un modo seguro. Y ¿cómo se podía estar más seguro? Como no había ni credo ni revelación divina, ni textos escritos, la comunidad apelaba al carácter tradicional de los ritos, tà nomizómena, y a la regularidad de las costumbres, tà pátria, y situaba el énfasis en la tradición. Sólo la tradición garantizaba la realización correcta de correctos rituales en la forma correcta y en el tiempo y el lugar correctos ${ }^{52}$. La tradición era el nómos, el fundamento de la religión y la piedad se centraba en la repetición y conservación de las costumbres rituales ancestrales. Como observaba Isócrates (VII 30), «la piedad no consiste en grandes gastos, sino en no cambiar nada de aquello que nos han transmitido nuestros antepasados»». La polis no era otra cosa que la comunidad de ciudadanos que aspira a sobrevivir y perpetuarse en el tiempo. Para ello era necesario que la comunidad cívica preservara las familias que la componían y gozara de la protección de los dioses. He aquí expuesto un elemento imperioso en la concepción religiosa griega: la transgresión de las normas por los individuos podía ser castigada por la divinidad y podía llegar a afectar a toda la comunidad. Por consiguiente, la demostración externa de la eusébeia, orientada al nómos, el culto, era un deber cívico, mientras que la asébeia atraía la ira de los dioses sobre toda la comunidad, no sólo sobre un individuo concreto, de ahí el vértigo del pensamiento socrático, y devenía, por lo tanto, en un delito políado, comunitario. La religión se convertía así en un factor esencial, insustituible, el único que hacía posible la cohesión de la comunidad; ya que no podía haber moral sin la autoridad de los dioses, los ciudadanos no podían constituir una polis y ésta no podía sobrevivir si no existía temor a los dioses.

Muy alejada de las concepciones socráticas y en palabras de Bruit Zaidman y Schmitt-Pantel 2002, p. 9,

la piedad ordinaria no era la expresión de un sentimiento de relación íntima con una divinidad, ni una necesidad de transformación interior. ... Ser eusebés

${ }^{51}$ McPherran 2011, pp. 120-122.

${ }^{52}$ Deacy 2007, p. 222; Hedrick 2007, p. 283; McPherran 2011, p. 112. 
significaba creer en la eficacia del sistema simbólico establecido por la polis para administrar las relaciones entre los hombres y los dioses, específicamente las prácticas rituales ancestrales, y además participar en dicho sistema de la manera más activa posible ${ }^{53}$.

De este modo, si los ciudadanos no abandonaban a los dioses, la comunidad de ciudadanos se vería a su vez protegida por ellos y nunca sería desamparada por los dioses. En la ética popular griega aparece, pues, como código fundamental honrar a los dioses y a los padres. Ambos aspectos se apoyaban el uno en el otro; ambos garantizaban la continuidad, la estabilidad de la comunidad y, en último término, el orden social y económico. Por el contrario, la asébeia quebraba la relación con los dioses y amenazaba la supervivencia de la propia comunidad cívica.

La duda socrática sobre los mitos, no sobre ellos mismos, sino como expresión de la voluntad de los dioses y fundamento del nómos tradicional, atentaba, en definitiva, contra las bases mismas sobre las que se asentaba la polis. De igual modo, las premisas socráticas de que los dioses eran a la vez buenos y autosuficientes chocaban con las creencias comunitarias. En los mitos los dioses no actuaban así. Si ellos eran buenos de acuerdo con las categorías de bondad aplicadas a los hombres, entonces muchas historias míticas sobre los dioses eran falsas. La solución cívica afirmaba que las categorías humanas de bondad no eran aplicables a los dioses. Dicho de una manera sencilla, si los dioses de la polis, los de la mitología, observaran las estrictas normas de la virtud socrática, que les obligaba a actuar sólo en lo que era bueno para los demás, en estas categorías austeras, serían irreconocibles, sufrirían una transformación ética que llevaría a la destrucción de los antiguos dioses y a la creación de otros nuevos, precisamente aquello de lo que se le acusaba ${ }^{54}$.

Rebatido en sus dos primeras argumentaciones, Eutifrón alega ahora, en su tercera definición, que la piedad es lo que es amado por todos los dioses

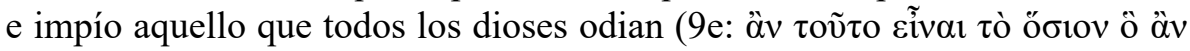

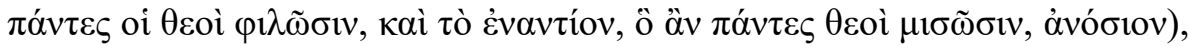
afirmación que es aceptada por Sócrates $(10 b-d)^{55}$. A partir de aquí Sócrates

${ }_{53}$ Cf. también Deacy 2007, pp. 222, 228-229, 233; Hedrick 2007, pp. 283-289.

${ }^{54}$ Smith y Woodruff 2000, p. 7.

${ }_{55}$ McPherran 1999, pp. 43-47; 2017, p. 117. Cf. también, por ejemplo, X., Mem. IV 3.17. 
introduce dos argumentos interrelacionados: pregunta a Eutifrón si «es lo pío lo amado por los dioses porque es piadoso, o es pío porque es amado por

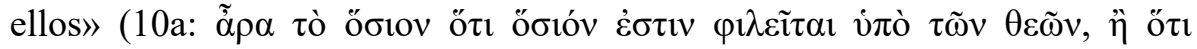

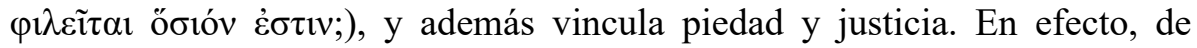
acuerdo con Sócrates, todo acto piadoso necesariamente ha de ser un acto justo, pero como resulta también evidente que la justicia es una noción más amplia que la piedad, lo pío es solamente una parte de lo justo (12d: ĩv $\delta \dot{\varepsilon}$

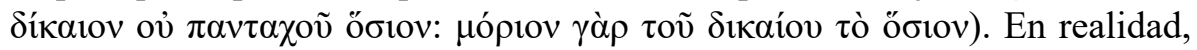
en el marco de su intelectualismo, Sócrates está apuntando la unidad de la virtud de la que tanto la piedad como la justicia forman parte ${ }^{56}$.

En esta parte del diálogo, Eutifrón ha sufrido una suerte de involución argumental y doctrinaria pues, si bien todavía mantiene una visión distante de lo tradicional en su idea de que existe una uniforme y racional conducta piadosa, intenta ahora conciliarla con la concepción enraizada en la ciudadanía que presentaba a los dioses como volubles y caprichosos.

Es Sócrates, en cambio, quien ha dado un paso más en su crítica a la piedad tradicional. La visión bastante voluntarista de una piedad definida por la referencia al amor de los dioses ha sido rechazada en favor de la idea de que la piedad es lo amado por los dioses a causa únicamente de que es piadoso. Las consecuencias lógicas de esta afirmación son absolutamente devastadoras para la piedad cívica y suponen una clara amenaza a la práctica religiosa popular. Es decir, lo pío es pío porque es pío, porque es justo, independientemente de la voluntad, acuerdo o desacuerdo de los dioses. En consecuencia, la voluntad de los dioses no sería útil para establecer lo que es piadoso ni puede servirnos de base para fundamentar las normas no escritas (nómoi). Además, Sócrates ha separado la piedad de los dioses y la ha relacionado con la justicia. Se trata de una vinculación que no deja de afectar al propio concepto de justicia. En efecto, si una parte de la justicia, precisamente la más vinculada a las creencias y prácticas religiosas, no tiene relación con la voluntad divina ni se basa en normas divinas, Sócrates está poniendo en duda la misma base teológica, religiosa, de la noción griega de justicia que la hace proceder directamente de los dioses.

En la cuarta definición ${ }^{57}$, Eutifrón y Sócrates coinciden en que la piedad es una parte de la justicia, por lo que es necesario, entonces, establecer con

\footnotetext{
56 Vallejo Campos y Vigo 2017, pp. 138-140.

${ }^{57}$ McPherran 2011, p. 117.
} 
precisión qué parte de la justicia corresponde a la piedad ${ }^{58}$. Eutifrón argumenta que lo pío es la parte de lo justo relativa al cuidado de los dioses y la parte restante de lo justo es la relativa al cuidado de los hombres ${ }^{59}$. Ahora bien, como indica Sócrates, si la piedad es el cuidado de los dioses tal como los hombres cuidan de los caballos, de los perros o de los bueyes y si todos ellos, esto es, la cosa cuidada, obtiene el beneficio de hacerse mejor, nosotros, a través de nuestros cuidados, ¿lograríamos hacer mejor a alguno de los dioses? (13a-e). Es evidente que tal cuestión debe responderse negativamente. Eutifrón matiza entonces su definición asegurando que la piedad es la parte de la justicia que es un servicio (hyperetiké) de los hombres a los dioses, similar a la que une a los esclavos con los amos o a los aprendices con el artesano (13d-b). Es decir, lo pío es la parte de lo justo relativa al cuidado de los dioses, entendiendo por este cuidado un servicio. Pero, para Sócrates, un servicio ayuda siempre al logro de algún resultado $\mathrm{y}$, por tanto, tendríamos que preguntarnos a qué obra divina contribuiríamos con nuestros servicios a los dioses (13d-e). Esta cuestión, a mi juicio, decisiva, queda sin respuesta. Volveremos más adelante sobre ella ${ }^{60}$.

Eutifrón aclara ahora, en la quinta y última definición, que la piedad es el arte del sacrificio y la plegaria, un servicio a los dioses por el que, recíprocamente, los dioses preservan las familias y las póleis y lo contrario destruye ambas $^{61}$. Esta afirmación de Eutifrón coincide exactamente con la piedad tradicional griega. Sócrates le replica alegando que esto sería una especie de intercambio comercial entre los dioses y los hombres (un tipo de emporía, cf. $14 \mathrm{~b} ; 14 \mathrm{c}-15 \mathrm{~b})^{62}$. En efecto, dice Sócrates, nosotros ofrecemos plegarias y sacrificios a los dioses, pero si ellos son los que otorgan, si nosotros no tenemos nada bueno que no proceda de los dioses, ¿en qué los beneficiamos nosotros? (14e). Eutifrón responde que los dioses reciben únicamente honra

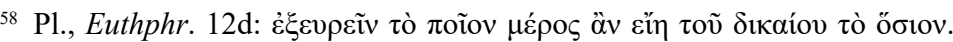

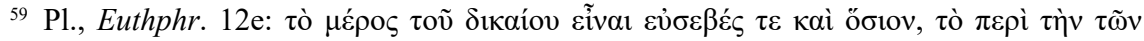

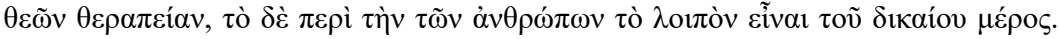

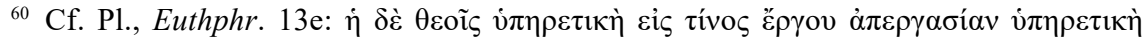
àv Eīi;

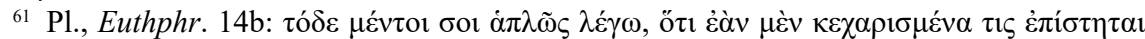

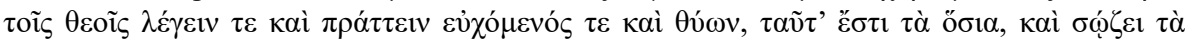

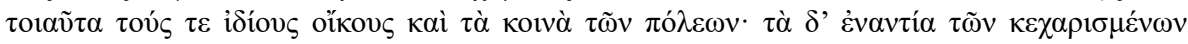

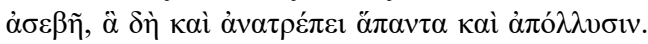

${ }_{62}$ West 1998, p. 14; McPherran 1999, pp. 52-54; 2011, p. 118. 
y veneración, nuestro deseo de complacerles, y que no necesitan los regalos que se les hace (15b). Sócrates le indica que ha vuelto a su anterior argumento, que ha sido ya rechazado, lo pío es lo que agrada a los dioses, y pide a Eutifrón que comiencen otra vez desde el principio su indagación (15c-d). Sin embargo, Eutifrón le pone como excusa que anda apurado de tiempo y, a pesar de las protestas de Sócrates, se marcha (15e-16a).

En el transcurso de esta última parte del diálogo Sócrates ha asentado dos afirmaciones importantes: la piedad es parte de la justicia que tiene que ver con las relaciones entre los dioses y los hombres $(12 \mathrm{e})^{63}$ y todas las cosas buenas proceden de los dioses (12d) ${ }^{64}$. En ambos casos, Sócrates se aparta de la creencia tradicional. En su primer postulado, se deriva, además, una consecuencia contraria a Eutifrón. Es decir, si la piedad es la parte de la justicia que concierne a nuestras relaciones con los dioses, obviamente hay otra parte de la justicia que compete a las relaciones de los hombres con otros hombres, que no es piadosa, por lo que no se puede decir que la acusación de Eutifrón a su padre, que concierne a otra persona, sea piadosa. Sócrates niega así la piedad filial como una parte de la piedad, sólo lo sería de la justicia no piadosa. Asimismo, de acuerdo con la piedad tradicional y en contra de la opinión de Sócrates, de los dioses proceden las cosas buenas y también las malas. Simplemente Sócrates, en su segunda proposición, está socavando el fundamento del culto en la medida en que éste sirve para granjearse la benevolencia de los dioses (de los dioses procede, según Sócrates, únicamente lo bueno). Ha vaciado de contenido la finalidad y esencia del culto. Sócrates da entender que los dioses prácticamente nada reciben de nosotros y que prácticamente para nada sirve el culto. Por último, frente a la creencia tradicional que piensa en un culto dirigido exclusivamente, unidireccional, a los dioses, Sócrates asegura que la piedad sirve para completar a los mortales.

En definitiva, aunque en cierto sentido inconcluso, en el Eutifrón, uniéndolo a la Apología, tenemos algunos elementos que nos permiten profundizar no sólo en la piedad socrática sino, sobre todo, en las consecuencias que se podían extraer de sus ideas para la piedad cívica.

Sócrates cree ciertamente que los actos piadosos son amados y agradables a los dioses, nunca duda de que toda acción piadosa es una relación virtuosa

${ }^{63}$ Herrmann 2007, p. 389.

${ }^{64}$ West 1998, p. 15. 
entre los hombres y los dioses que agrada a los dioses (14e-15a), y añade (14c-15a) que no hay nada bueno para nosotros que no den los dioses y que el servicio a los dioses es de la mayor importancia para él (14d). Sócrates considera que los sacrificios tradicionales son piadosos, pero éstos no constituyen, en su opinión, la totalidad de la práctica religiosa. Para el filósofo la piedad es ante todo un tipo de conocimiento objetivo y racional, es la parte de la justicia que es el servicio de los hombres a los dioses, asistiendo a los dioses en su obra, érgon, una obra que produce buenos resultados (11e-14b). Por lo tanto, si la piedad es un servicio que ayuda a los dioses, debe existir un proyecto en el que los dioses estén de acuerdo, a las que las acciones piadosas sirvan y promuevan. De hecho, los dioses han dejado nuestras almas incompletas en términos de conocimiento por alguna razón cuando podían haber realizado buenas almas humanas ${ }^{65}$. Esa obra de los dioses a la que debemos servir es, dicho de una manera sencilla, hacernos mejores, completar nuestras almas. En último término, el servicio a los dioses es el conocimiento de la virtud, esto es, la forma de vida filosófica (Pl., Ap. 30a $)^{66}$.

Ahora bien, ¿qué supone esta piedad socrática para la piedad cívica? La piedad socrática no está gobernada por Zeus ni por las costumbres tradicionales, sino que su pensamiento racional prima sobre la tradición o la autoridad. Frente al ciudadano normal que concebía la piedad como las prácticas reconocidas y la aceptación de la autoridad de las historias narradas por los poetas y pintadas en los templos (6b), Sócrates propugna que los relatos mitológicos y los dioses que los protagonizan no nos permiten conocer la piedad ni la relación que existe entre la piedad y la justicia. Sócrates introduce además un limitado agnosticismo, de modo que considera que existen los dioses, pero nuestro conocimiento de su naturaleza y relación con nosotros es extremadamente limitado. El conocimiento pleno de los dioses está simplemente fuera del poder finito del conocimiento humano. Frente a sus ideas, la religión tradicional presuponía un más extenso conocimiento de los dioses ( $\mathrm{Pl}$., Ap. 23b).

Como lo pío no puede ser, en la concepción socrática, aquello que agrade a todos los dioses, se ve así impugnado el culto griego basado en una concepción contractual o legalista, comercial diría Sócrates, de la relación entre

\footnotetext{
${ }^{65}$ Hermann 2007, p. 390.

${ }^{66}$ West 1998, pp. 14-15.
} 
hombres y dioses. Sócrates apuntaba a la irrelevancia de las tradicionales instituciones religiosas de la polis, de la participación en las ceremonias religiosas supervisadas por la polis, en los festivales, en los sacrificios requeridos, y de las acciones que trataban de evitar las fuentes tradicionales de polución. Esto no quiere decir que Sócrates no participara en las habituales ceremonias religiosas cívicas o que criticara a quien lo hiciera. Pudo pensar que eran incluso formas externas necesarias para la piedad. Lo importante es que negaba que fueran condiciones suficientes. La religión tradicional quedada reducida a una mera forma de conducta externa y aquellos que únicamente seguían las prácticas tradicionales y no hacían nada más no eran completa y verdaderamente piadosos y establecían una relación equivocada con los dioses. La justicia y la piedad, que es parte de la justicia, no se basaban en la voluntad de los dioses y quedaban así desprovistas de cualquier origen o significación teológica ${ }^{67}$. Era necesario buscar otra justificación que las fundamente. Esto explica por qué se le acusaba de no creer en los dioses que creía la ciudad. Los dioses de la ciudad eran aquellos que estaban bien dispuestos por los sacrificios tradicionales y las costumbres y, en este sentido, es verdad que Sócrates no creía en los dioses que creía la ciudad. Sencillamente, debilitaba la religión comunitaria. Y el hombre antiguo era un hombre religioso y la religión era hegemónica en la comunidad ciudadana.

Un último aspecto presente en el Eutifrón tiene que ver con la señal (sémeion) ${ }^{68}$ o voz (phoné) ${ }^{69}$ que Sócrates percibía de manera privada e individual, que le llegaba de manera impredecible y que le protegía de las malas acciones. El filósofo le atribuía un origen divino y la definía como daimónion $t i$ (algo demónico) ${ }^{70}$. De hecho, cuando Sócrates le dice a Eutifrón que había sido acusado de introducir nuevos dioses, el adivino le replica inmediatamente que la causa debía hallarse en que Sócrates aseguraba que el daimónion

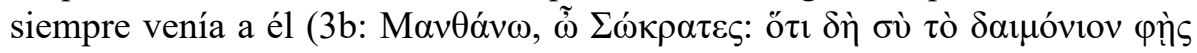

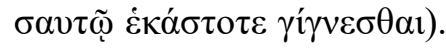

Ciertamente el concepto de daimónion existía en la religión griega como un elemento personal intermediario que, en último término, poseía un origen divi-

${ }^{67}$ West 1998, p. 15.

${ }^{68}$ Pl., Ap. 40b1, c3; Euthd. 272e4; Phdr. 242b9; R. 496c4; Mem. 1.1.3-5.

${ }^{69}$ Pl., Ap. 31d1; Phdr. 242c2; X., Apol. 12.

${ }^{70}$ Véase P1., Ap.31c-d; Smith y Woodruff 2000, pp. 9-10; Kraut 2000, p. 16; Brickhouse y Smith 2000, pp. 74-88; Long 2006, pp. 63-74. 
no y también como la parte oscura de la acción de los dioses, como una fuerza imprevisible, externa al hombre, causante de sucesos inexplicables. Uno podía poseer un daimónion personal que no entraba en contradicción con la creencia convencional de que los dioses guiaban a todos. Sin embargo, nadie había defendido nunca que recibiera una guía tan directa y personal que le impulsara a tomar decisiones que podían ser contrarias a la comunidad. Se trataba de un signo providencial, que era percibido sólo por él y de una manera tan poderosa que implicaba una intimidad con lo divino que podía despertar sospechas en la comunidad $^{71}$. Esta señal divina podía ser fácilmente interpretada como un nuevo dios superior que podría reemplazar a las divinidades cívicas. De hecho, a los ojos de los ciudadanos la exclusividad religiosa constituía un verdadero peligro, que amenazaba la unidad comunitaria que basaba precisamente su estabilidad y duración en la benevolencia de los dioses, de todos los dioses y no de uno solo ${ }^{72}$. Sólo la totalidad de los dioses abarcaba toda la realidad y la piedad nunca se consideró como la devoción a un solo dios ${ }^{73}$. La explicación era bastante simple: la veneración a un solo dios podía atraer hacia la comunidad la ira del resto. Con su daimónion, Sócrates parecía sugerir también que era superior a otro ciudadano y no ocultó este sentimiento de superioridad. Sócrates podía estar rindiendo culto a una divinidad no aprobada por la polis, él mismo hacía hincapié en su relación privada y especial con ella, que, en cierta medida, parecía oponerse a los cultos y a la vida comunitaria ${ }^{74}$.

Y, así, finalmente Sócrates fue llevado a juicio y condenado. La piedad, la impiedad y la justicia eran también cuestiones legales. La piedad se plasmaba en el culto y la justicia, en los tribunales. Fue juzgado en la Heliea ${ }^{75}$ y, tras el juicio, fue conducido a la prisión del ágora ${ }^{76}$. Transcurrió un mes hasta que un día, cerca del crespúsculo, el sirviente de los Once, los magistrados encargados de las ejecuciones, le anunció que la hora había llegado. Finalmente bebió la cicuta ${ }^{77}$. Sócrates no vería un nuevo amanecer.

71 X., Ap. 14; Bussanich 2006, 206.

${ }_{72}$ Cf. Bruit Zaidman y Schmitt-Pantel 2002, pp. 7-8.

73 Bremmer 2006, p. 23; Burkert 2007, p. 293.

${ }_{74}$ McPherran 2011, pp. 125, 132-133.

${ }^{75}$ Para una discusión sobre la Heliea y su localización véase Hansen 1989, pp. 219-261. Sobre sus atribuciones cf. MacDowell 1978, pp. 29-33.

${ }^{76}$ Wycherley 1973, pp. 149-150; Vanderpool 1975, pp. 18-31.

${ }_{77}$ Pl., Phd. 117d-118a; Bloch 2002, pp. 255-278. 
Se podría pensar que los motivos para la acusación de Sócrates fueron más políticos que religiosos. Que se fabricaron endebles cargos religiosos para asegurar su ejecución, cuando la imputación real contra Sócrates era la de sedición, ya que había estado asociado con oligarcas como Alcibíades o Critias y, como el acuerdo de reconciliación del año 403 impedía incoar este tipo de proceso político, se recurrió a una graphè asébeias.

Ciertamente un relevante factor de la impopularidad de Sócrates fue su estrecha relación con determinados personajes como Alcibíades y Critias. Además, Sócrates no intentó ocultar al jurado que era crítico con la democracia y afirmó que los muchos se corrompen, que sólo los pocos son expertos (Pl., $A p .25 b)$ y que un jurado democrático inevitablemente conllevaba injusticia e ilegalidad (Pl., Ap. 31e). Su pensamiento antipopular pudo concitar rechazo. Nadie dice que era un oligarca pero su filosofía tuvo un componente antidemocrático ${ }^{78}$.

Es posible pensar también que la influencia de las circunstancias fue determinante. En 399, hacía cinco años que Atenas había sufrido una infausta derrota en el Guerra del Peloponeso. A los desastres causados por este largo conflicto, que se había prolongado durante veintisiete años, a las plagas, la pérdida del imperio, de los tributos, de la flota, y a las bajas incontables, en torno quizá al $40 \%$ del cuerpo ciudadano, hubo que sumar una postguerra catastrófica que había visto la ocupación espartana, el establecimiento de un régimen oligárquico, protagonizado por un consejo de Treinta ciudadanos, encabezados por Critias y que había llevado a la muerte a centenares de ciudadanos, y además una guerra civil, una nueva intervención militar espartana y la restauración de la democracia con el establecimiento de una amnistía que no dejó de crear tensiones en el seno del cuerpo cívico en los años venideros ${ }^{79}$.

La explicación a todas estas funestas desventuras que se habían abatido sobre la ciudad, en la mentalidad de cualquier ateniense, no tenía que ser exclusivamente política ni unívoca. A diferencia de nuestras modernas concepciones contemporáneas, que tienden a separar iglesia y estado, la religión griega estaba completamente integrada en la polis, en la comunidad, hasta el punto de que no había una sola esfera de la vida que no tuviera su vertiente religiosa y

\footnotetext{
${ }_{78}$ Kraut 2000, pp. 15-19; Parker 2000, pp. 40-54.

${ }^{79}$ En general sobre este período pueden consultarse Pascual 1997, pp. 39-48; Fornis 2008, pp. 60-70.
} 
cualquier acción religiosa, como hemos visto, no era una mera cuestión exclusivamente privada, sino que podía afectar a toda la comunidad. Y los atenienses eran plenamente conscientes, ya desde el último tercio del siglo $\mathrm{V}$, del peligroso juego de la ciudad con el ateísmo y la impiedad. Sirvan como ejemplo los juicios contra Anaxágoras ${ }^{80}$ y Protágoras $^{81}$, los sobrecogedores asuntos de la mutilación de los Hermes y la parodia de los Misterios eleusinos en $415^{82}$, el debate entre physis y nómos, que cuestionaba la tradición, por ejemplo, en el trato que debía darse a los melios en $416^{83}$, y la relajación de las costumbres morales, que emergen preocupantes en el relato de Tucídides ${ }^{84}$.

En este sentido, Sócrates da también una explicación en la Apología de las razones por las cuales fue llevado a juicio. Afirma que, durante largo tiempo, había sido víctima de falsas acusaciones, de que investigaba los fenómenos astronómicos y geológicos desde un punto de vista ateo ${ }^{85} \mathrm{y}$ que fue confundido con los sofistas y los filósofos de la physis, con la sospecha de que sus actividades eran impías y corruptoras de la moral cívica, y de que sus ideas creaban un conflicto entre piedad y explicación de la naturaleza. Sócrates pudo tener razón en este punto ${ }^{86}$.

Todos estos supuestos ataques a la tradición pudieron, en la mente de muchos ciudadanos, haber atraído la catástrofe, y muchos pudieron pensar que las desgracias acaecidas habían sido enviadas por los dioses como castigo por la impiedad de la polis y considerar que era necesario purificar la ciudad. Este deseo de purificación se sintió ya antes del final de la Guerra del Peloponeso. No en vano, en 410/9 se emprendió una codificación y depuración de las leyes, llamadas de Dracón y Solón, que se referían sobre todo a leyes sagradas y a la renovación del calendario de sacrificios, y que se colocaron precisamente en la Estoa Real ${ }^{87}$. La conciencia de todas estas desven-

\footnotetext{
${ }^{80}$ Plu., Per. 32.1-5.

${ }^{81}$ Cuyos libros fueron quemados en el Ágora (cf. D.L. IX 52, 54, 55; D.S. XII 39.2; Ath. 589e; Sch. Ar., Eq.969).

82 Th. VI 27-29; 60-62; And. I 34-69.

${ }^{83}$ Th. V 81-113.

${ }^{84}$ Th. II 50-53.

${ }^{85} \mathrm{Pl}$., Ap. 1b-c; $26 \mathrm{~d}$.

${ }^{86}$ Kraut 2000, pp. 13-14; Nails 2006, p. 10; Wooddruff 2006, pp. 36-47; Hedrick 2007, p. 285.

${ }^{87}$ La Estoa era utilizada en época de Sócrates como archivo para las leyes de la ciudad. Según Aristóteles (Ath. 4.1, 7.1; cf. And. I 83; Plu., Sol. 17.1), las leyes de Solón se encon-
} 
turas, el deseo de expiación y de abrir un tiempo nuevo y renovado pudo ser aún mayor tras el turbulento período de Postguerra y estaría presente, de una manera difusa cuando menos, en el año 399. Muchos atenienses pudieron creer que Sócrates era uno de aquellos que, con sus opiniones y enseñanzas, había atraído la ira de los dioses sobre la comunidad. El prejuicio contra los intelectuales y científicos, sus sentimientos antidemocráticos, la actuación de algunos de sus discípulos como Alcibíades o Critias, el carácter elitista de su grupo de néoi, su actitud provocadora, su espíritu de contradicción, su presunción de superioridad pudieron pesar en su contra, pero los atenienses que formaron el jurado en aquella primavera del 399 pudieron percibir sobre todo una falta de piedad que minaba las prácticas religiosas tradicionales, a la que se añadía su pretensión de comunicarse íntima y singularmente con la divinidad, una pretensión que le situaba y por la que se asignaba a sí mismo una posición privilegiada en la comunidad, incompatible con la lealtad y el buen ciudadano; pudieron juzgar que su actitud no era verdaderamente justa ni pía, que podía crear nuevas divinidades y arrinconar los cultos tradicionales y que estaba extendiendo su deslealtad, su arrogancia y el descrédito de la tradición entre los jóvenes. De hecho, la acusación a Sócrates no fue un hecho aislado sino que, en ese mismo año, tuvieron lugar otros procesos de impiedad como los de Andócides ${ }^{88}$ y Nicómaco, protagonista este último del discurso trigésimo de Lisias ${ }^{89}$.

En suma, Sócrates pudo ser objeto de la reacción del cuerpo ciudadano que, angustiado por años catastróficos, «se sentía amenazado en su unidad, siendo como era la religión una parte indisociable de su identidad $\gg^{90}$. La acusación de impiedad ha de ser tomada en serio y no como un mero pretex-

traban aquí y una estela de mármol descubierta en 1843, durante la construcción de la nueva catedral, a unos $700 \mathrm{~m}$ al este de la Estoa, nos indica que la revisión de las leyes de Dracón sobre el homicidio, concluida en el año 409/8, fue dispuesta en el frente del Pórtico real. Precisamente dos alas fueron construidas en la Estoa entre los años 410 a 400 para albergar dichas leyes y, de hecho, en el umbral de la Stoá Basíleios, entre los intercolumnios del frente exterior, quedan todavía los huecos en donde se encajaron las estelas, resultado de esta recopilación legislativa, para que fueran vistas por ambas caras $\left(I G \mathrm{I}^{2} 105\right.$, esp. 11. 7-8; Stroud 1968; Robertson 1990, pp. 43-75; Rhodes 1991, pp. 87-100).

${ }^{88}$ Discurso primero.

89 Nails 2006, pp. 5-7. Para la influencia de otros procesos por impiedad: Waterfield 2009, pp. 32-33.

${ }^{90}$ Bruit Zaidman y Schmitt-Pantel 2002, p. 8, aunque referida en general a la impiedad. 
to. Fue un juicio religioso, no un juicio político enmascarado. De este modo, Sócrates pudo haber desempeñado el papel de víctima propiciatoria para la ciudad. Propugnaba demoledores ideas sobre los dioses y el culto y los atenienses querían desembarazarse de las tendencias indeseables y, como acaecía en el ritual de las Targelias, buscaron un phármakon para favorecer la regeneración de Atenas ${ }^{91}$. Como eutifrones, ellos se consideraban buenos ciudadanos y amantes de los dioses, pero al mismo tiempo eran capaces de condenar a Sócrates. Ellos... ¿Y nosotros?

\section{BiBLIOGRAFÍA}

Bendlin, A. 2007: «Purity and Pollution», en Ogden, D. (ed.), A Companion to Greek Religion, Oxford, Blackwell, pp. 178-189.

Bloch, E. 2002: «Hemlock Poisoning and the Death of Socrates: Did Plato Tell the Truth?», en Brickhouse, Th. C. y Smith N. D. (eds.), The Trial and Execution of Socrates: Sources and Controversies, Nueva York-Oxford, Oxford University Press, pp. 255-278.

Bonnechere, P. 2007: «Divination», en Ogden, D. (ed.), A Companion to Greek Religion, Oxford, Blackwell, pp. 145-160.

Bremmer, J. N. 2006: La religión griega, dioses y hombres, santuarios, rituales y mitos, Córdoba, El Almendro.

Brickhouse, Th. C. y Smith, N. D. 1989: Socrates on Trial, Princeton, Princeton University Press.

Brickhouse, Th. C. y Smith, N. D. 2000: «Socrates' Gods and the Daimónion», en Smith, D. y Woodruff, P. (eds.), Reason and Religion in Socratic Philosophy, Oxford, Oxford University Press, pp. 74-88.

Bruit Zaidman, L. y Schmitt-Pantel, P. 2002: La religión griega en la polis en época clásica, Madrid, Akal.

Burkert, W. 2007: Religión griega arcaica y clásica, Madrid, Abada.

Bussanich, J. 2006: «Socrates and Religious Experience», en Abbel-Rappe, S. y

Kamtekar, R. (eds.), A Companion to Socrates, Oxford, Blackwell, pp. 200-213.

Camp, J. 2001: The Archaeology of Athens, New Haven-Londres, Yale University Press.

Colaiaco, J. A. 2001: Socrates against Athens: Philosophy on Trial, Londres, Routledge. Connor, W. R. 1991: «The Other 399: Religion and the Trial of Socrates», en Flower, M. A. y Toher, M. (eds.), Georgica. Greek Studies in Honour of Geor-

\footnotetext{
91 Waterfield 2009, pp. 202-204.
} 
ge Cawkwell, Bulletin Supp. 58 of the Institute of Classical Studies, Londres, pp. $49-56$.

Deacy, S. 2007: «Famous Athens, Divine Polis: The Religious System at Athens», en Ogden, D. (ed.), A Companion to Greek Religion, Oxford, Blackwell, pp. 221-235.

Euben, J. P. 1997: Corrupting Youth: Political Education, Democratic Culture, and Political Theory, Princeton, Princeton University Press.

Fornis, C. 2008: Grecia exhausta. Ensayo sobre la Guerra de Corinto, Gotinga, Vandenhoeck \& Ruprecht.

Hansen, M. H. 1989: «The Athenian Heliaia from Solon to Aristotle», en Hansen, M. H., The Athenian Ecclesia II: A Collection of Articles 1983-1989, Copenhague, Museum Tusculanum Press, pp. 219-261.

Harrison, A. R. W. 1971: The Law of Athens. Volume II: Procedure, Oxford, Oxford University Press.

Hedrick Jr, Ch. W. 2007: «Religion and Society in Classical Greece», en Ogden, D. (ed.), A Companion to Greek Religion, Oxford, Blackwell, pp. 283-296.

Herrmann, F.-G. 2007: «Greek Religion and Philosophy: The God of the Philosopher», en Ogden, D. (ed.), A Companion to Greek Religion, Oxford, Blackwell, pp. 385-397.

Janko, R. 2006: «Socrates the Freethinker», en Abbel-Rappe, S. y Kamtekar, R. (eds.), A Companion to Socrates, Oxford, Blackwell, pp. 48-62.

Kraut, R. 1984: Socrates and the State, Princeton, Princeton University Press.

Kraut, R. 2000: «Socrates, Politics and Religion», en Smith, D. y Woodruff, P. (eds.), Reason and Religion in Socratic Philosophy, Oxford, Oxford University Press, pp. 13-23.

Leslie Shear Jr., T. 1971: «The Athenian Agora: Excavations of 1970», Hesperia 40, pp. 241-279.

Leslie Shear Jr., T. 1975: «The Athenian Agora: Excavations of 1973-1974», Hesperia 44 , pp. 331-374.

Long, A.A. 2006: «How Does Socrates' Divine Sign Communicate with Him?», en Abbel-Rappe, S. y Kamtekar, R. (eds.), A Companion to Socrates, Oxford, Blackwell, pp. 63-74.

MacDowell, D. M. 1978: The Law in Classical Athens, Ithaca, Cornell University Press.

McPherran, M. L. 1999: The Religion of Socrates, Filadelfia, Pennsylvania State University Press.

McPherran, M. L. 2005: «Justice and Pollution in the Euthyphro», en Kamtekar, R. (ed.), Plato's Euthyphro, Apology and Crito. Critical Essays, Lanhan, Maryland, Rowman \& Littlefield, pp. 1-22.

McPherran, M. L. 2011: «Socratic Religion», en Morrison, D. R. (ed.), The Cambridge Companion to Socrates, Cambridge, Cambridge University Press, pp. 111-133. 
Nails, D. 2006: «The Trial and Death of Socrates», en Abbel-Rappe, S. y Kamtekar, R. (eds.), A Companion to Socrates, Oxford, Blackwell, pp. 5-20.

Ober, J. 2011: «Socrates and Democratic Athens», en Morrison, D. R. (ed.), The Cambridge Companion to Socrates, Cambridge, Cambridge University Press, pp. $138-178$.

Plácido, D. 1984-85: «Ánito», Studia Historica 2-3, pp. 7-13.

Parker, R. 1996: Athenian Religion. A History, Oxford, Clarendon.

Parker, R. 2000: «The Trial of Socrates: And a Religious Crisis», en Smith, D. y Woodruff, P. (eds.), Reason and Religion in Socratic Philosophy, Oxford, Oxford University Press, pp. 40-54.

Parker, R. 2005: Polytheism and Society at Athens, Oxford, Oxford University Press.

Pascual, J. 1997: Grecia en el siglo IV a.C. Del imperialismo espartano a la muerte de Filipo de Macedonia, Madrid, Síntesis.

Prior, W. J. 2019: Socrates, Cambridge, Polity Press.

Rhodes, P. J. 1991: «The Athenian Code of Laws, 410-399 B.C.», JHS 111, pp. 87-100.

Robertson, N. 1990: «The Law of Athens, 410-399 B.C.: The Evidence for Review and Publication», JHS 110, pp. 43-75.

Segvic, H. 2006: «No One Errs Willingly: The Meaning of Socratic Intellectualism», en Abbel-Rappe, S. y Kamtekar, R. (eds.), A Companion to Socrates, Oxford, Blackwell, pp. 171-185.

Smith, D. y Wooddruff, P. 2000: «Introduction», en Smith, D. y Wooddruff, P. (eds.), Reason and Religion in Socratic Philosophy, Oxford, Oxford University Press, pp. 1-12.

Stone, I. F. 1988: The Trial of Socrates, Nueva York, Little, Brown and Co.

Stroud, R. S. 1968: Drakon's Law on Homicide, Berkeley-Los Ángeles, University of California Press.

Vallejo Campos, A. y Vigo, A. G. 2017: Filósofos griegos: de los sofistas a Aristóteles, Pamplona, EUNSA.

Vanderpool, E. 1975: «The State Prison of Ancient Athens», en DeVries, K. (ed.), From Athens to Gordion. The Papers of a Memorial Symposium for Rodney S. Young, University of Pennsylvania Press: Filadelfia, pp. 18-32.

Vlastos, G. 1983: «The historical Socrates and Athenian Democracy», Political Theory 11, pp. 495-516.

Vlastos, G. 1995: Socratic Studies, Cambridge, Cambridge University Press.

Vlastos, G. 2000: «Socratic Piety», en Smith, D. y Wooddruff, P. (eds.), Reason and Religion in Socratic Philosophy, Oxford, Oxford University Press, pp. 55-73.

Waterfield, R. 2009: Why Socrates Died: Dispelling the Myths, Nueva York, W. W. Norton \& Co. 
West, Th. G. 1998: «Introduction», en West, Th. G. y West, G. S. (eds.), Four Texts on Socrates. Plato's Euthyphro, Apology and Crito, and Aristophanes' Clouds, Ithaca, Cornell University Press, pp. 9-40.

Wood, E. M. y Wood, N. 1978: Class Ideology and Ancient Political Theory: Socrates, Plato, and Aristotle in Social Context, Oxford, Oxford University Press.

Wooddruff, P. 2006: «Socrates among the Sophists», en Abbel-Rappe, S. y Kamtekar, R. (eds.), A Companion to Socrates, Oxford, Blackwell, pp. 36-47.

Wycherley, R. E. 1973: The Athenian Agora. Vol 3: The Literary and Epigraphical Testimonia. Reimpr. Princeton, Princeton University Press. 